\title{
Birth Order, Father's Occupation and Family Size are Strongly Associated with Thinness Among Bengalee Adolescent Girls of Darjeeling District, West Bengal (India)
}

\author{
Debnath $\mathrm{M}^{1}$, Tigga $\mathrm{PL}^{2}$, Mondal $\mathrm{N}^{3}$, Sen $\mathrm{J}^{4}$ \\ ${ }^{1}$ Mampi Debnath, M.Sc. Ex- Post Graduate \\ Student, Department of Anthropology, \\ University of North Bengal, ${ }^{2}$ Pushpa Lata Tigga, \\ M.Sc. UGC-Rajiv Gandhi Fellow, Department \\ of Anthropology, University of North Bengal, \\ ${ }^{3}$ Nitish Mondal, M.Sc, Ph.D. Assistant \\ Professor, Department of Anthropology, \\ Assam University (Diphu Campus), Assam, \\ India, ${ }^{4}$ Jaydip Sen, M.Sc, Ph.D. Professor, \\ Department of Anthropology, University of \\ North Bengal, India.
}

\section{Address for correspondence:}

Jaydip Sen, M.Sc, Ph.D. Professor,

Department of Anthropology,

University of North Bengal, Raja Rammohunpur,

Dist: Darjeeling 734013, West Bengal, India.

Tel: +91-9932268224

E-mail: jaydipsen@rediffmail.com

Acknowledgements: The authors acknowledge the extended help and cooperation of school authorities, subjects and their parents.

Funding: Nil

Conflict of Interest: None

Permission from IRB: Yes

Ethical dilemmas faced during study: No

\section{How to cite}

Debnath M, Tigga PL, Mondal N, Sen J. Birth Order, Father's Occupation and Family Size are Strongly Associated with Thinness Among Bengalee Adolescent Girls of Darjeeling District, West Bengal (India) . J Nepal Paediatr Soc 2016;36(2):115-120.

doi: http://dx.doi.org/10.3126/jnps.v36i2.15520

This work is licensed under a Creative Commons Attribution 3.0 License.

\begin{abstract}
Introduction: Undernutrition is a major issue in the developing countries such as India. The country has the largest adolescent population in the world and one of the primary focuses of nutritional assessment among them is undernutrition. The present cross-sectional study tries to determine the prevalence of thinness among adolescent girls of Darjeeling district using thinness (BMI-for-age) and to ascertain the effects of different socio-economic and demographic variables on the same. Material and methods: The study was carried out among 387 school-going adolescent girls aged 9-14 years belonging to the Bengalee Hindu caste populations (BHCP). The prevalence of thinness was assessed using recently proposed international BMI-for-age cut-offs of Cole et al. Results: The prevalence of overall thinness was $23.77 \%$. The distribution of mild (Grade I), moderate (Grade II), and severe (Grade III) thinness were $17.31 \%, 4.39 \%$ and $2.07 \%$, respectively. The results of the binary logistic regression analysis showed that birth order, family size and father's occupation were significantly associated with overall prevalence of thinness $(p<0.05)$. Conclusion: The proper dissemination of awareness related to nutritional requirement, food habit, and appropriate dietary habit would be helpful to reduce the prevalence of thinness.
\end{abstract}

Key words: Thinness, Birth order, Family size, Anthropometry, Public Health, Adolescents

\section{Introduction}

U ndernutrition is a major public health problem in the developing countries. In India, one of the primary focuses of nutritional assessment is undernutrition among adolescents. Adolescence is the transition period between childhood and adulthood and is characterized by a rapid period of growth ${ }^{1}$. India has the largest adolescent population in the world and about $21 \%$ of the Indian population are adolescents. It may be mentioned here that South Asia is the home to almost half $(42.0 \%)$ of all early aged marriages ( $<18$ years) worldwide, and India alone accounts for one third (33.0\%) of the global total ${ }^{3}$. Therefore, the nutritional status of adolescent girls, the future mothers, bear special significance as they contribute significantly to the nutritional status of the populations. They have high 
energy requirements due to rapid physical growth ${ }^{1}$ and faced with several challenges related to poor knowledge and lack of awareness about physical and psychological changes that occurs during adolescence and also the illhealth conditions, lack of access to health care services, lack of education and unsafe environment ${ }^{2}$.

There is a need to develop a database on the nutritional status of adolescents from different parts of the country. This will enable the government and nongovernmental agencies to formulate policies and initiate strategies for well-being of the adolescents. It is recently that some efforts have been made to include adolescents as beneficiaries in some of the health care and nutritional intervention programmes by the Government of India 4 . Subsequently, a sizeable number of studies have been reported on the prevalence of adolescent undernutrition in Indian population $4,5,6,7,8,9,10,11$.

The body mass index-for-age (BMI-for-age) has been proposed by Cole et al $^{12}$. to be the best surrogate anthropometric measures of thinness (low-BMl-for-age) among children and adolescents. It has been opined that undernutrition could be better assessed in terms of thinness ${ }^{12}$. Studies have also reported that prevalence of thinness is influenced by several socio-economic and demographic factors ${ }^{13,14,15,16,17}$.

Given the above, information on prevalence of thinness among adolescent girls of the developing countries such as India, where a vast segment of the population is undernourished and underprivileged, are needed to be generated for national and international comparisons. Nutritional requirements during adolescence are considered to be generally high due to physical attainment, especially during early adolescent stages. Poor attainments of physical growth will certainly lead to several ill-health and physical performance related issues among them. The effects of different socio-economic and socio-demographic variables on thinness also need to be documented.

Therefore, keeping these issues in mind, the aim of the present study was to estimate prevalence of thinness among adolescent girls of Darjeeling district, and to ascertain the effects of different socio-economic and demographic factors on the same.

\section{Material and Methods}

The present cross-sectional study was conducted among 387 school-going adolescent girls belonging to the Bengalee Hindu Caste Populations (BHCP) aged between 9-14 years residing in the areas of Matigara
Block under Siliguri sub-division of Darjeeling district, West Bengal. Ethnically, the BHCP is a Bengali-speaking endogamous caste group of West Bengal and faithful to Hinduism. They are probably a blend of Dravidian and Mongoloid ethnic groups with a strain of Indo-Aryan blood among the higher caste groups ${ }^{18}$. The minimum number of sample size required for reliable estimate and assessment of nutritional status was calculated utilizing a standard sample size estimation procedure ${ }^{19}$. In this method, the anticipated population proportion of $50 \%$, absolute precision of $5 \%$ and confidence interval of $95 \%$ were considered. The minimum sample thus estimated size in this study was estimated to be 384 individuals.

A total of three secondary schools were selected for collection of data. The schools were selected based on easy road access and identical student strength. Age was recorded from the school records and birth certificates. Verbal consent was taken from parents and the girls prior to collection of data. Participation was purely voluntary in nature. Those suffering from any physical or limb deformities and suffering from any disease at the time of data collection were excluded. Necessary study permissions were obtained from the schools prior to data collection. The study was conducted according to the ethical guidelines for human experiments as laid down in the Helsinki Declaration of $2000^{20}$. A stratified random sampling method was used to select the girls. A total of 425 apparently healthy adolescent girls belonging to the BHCP was initially approached to participate in the study and also in order to achieve the minimum sample size estimated earlier. Of these 425 girls, 12 of them declined to participate in the study and 26 girls were excluded because of their ages were not in the age group selected (9-14 years). The overall participation rate in the study was $97.18 \%$. Anthropometric measurements of height and weight were recorded using standard procedures ${ }^{21}$. The interobserver and inter-observer technical errors of the measurement (TEM) were calculated for testing the reliability of the data following the method of Ulijaszek and Kerr. ${ }^{22}$

Prevalence of thinness (low BMI-for-age) has been assessed following the international BMI cut-off points as proposed by Cole et al. ${ }^{12}$ The BMI values were used to determine three definite grades of thinness (Grade I: mild, Grade II: moderate, Grade III: severe). These grades are similar to the different chronic energy deficiency grades based on BMI among adults. ${ }^{1}$. Hence, a girl observed to be below thinness grades of Grade I, II, III of age and sex-specific cut-offs has been classified as mild, moderate and severely thin respectively. ${ }^{12}$ 
Socio-economic and demographic data were recorded using a structured schedule. The girls as well as one of their parents were subsequently interviewed to collect the required information. The schedule was completed both school and household visits. The data recorded were on sex, age, birth order, mother's education, father's education, ethnic group, mother's occupation, father's occupation, house type, household income and family size.

The data was statistically analyzed using the Statistical Package of Social Science (SPSS: version 17.0). One way analysis of variance (ANOVA) was also done to assess mean differences among agegroups. Chi-square analysis was performed to assess differences in prevalence of thinness among socioeconomic and demographic variables. Binary logistic regression (BLR) analysis was fitted to estimate the crude odds ratios (ORs) and 95\% confidence intervals (Cls) associated with thinness. The BLR analysis allows the creation of categorical depended variables and the odds were obtained by comparing with the reference category. To create dichotomous dependent variables, thinness was coded as ' 1 ' and normal was coded as ' 0 ' in regression models respectively. The predictor variables were age, birth order, mother's education, father's education, mother's occupation, father's occupation, house type, household income and family size were entered as dummy variables and results were obtained by comparing with reference categories. A p-value of $<0.05$ and $<0.01$ were considered to be statistically significant.

\section{Results}

The age-specific mean and standard deviation $( \pm)$ of height, weight, BMI and prevalence of different grades of thinness are presented in Table 1. The overall mean height, weight and BMI among the adolescent girls were $140.68 \pm 9.98 \mathrm{~cm}, 35.67 \pm 10.01 \mathrm{~kg}$ and $17.72 \pm 3.31 \mathrm{~kg} /$ $\mathrm{m}^{2}$ respectively. The age-specific mean height, weight and BMI values gradually increased with age. The agespecific mean BMI ranged from $15.85 \mathrm{~kg} / \mathrm{m}^{2}$ (in 9 years) to $20.29 \mathrm{~kg} / \mathrm{m}^{2}$ (in 14 years). Using ANOVA, the age- specific mean differences were found to be statistically significant in height (F-value: 80.30 , d.f.: 5,386 ), weight (F-value: 50.22, d.f.: 5,386) and BMI (F-value: 15.83, d.f.: $5,386)(p<0.01)$. The prevalence of overall thinness was observed to be $23.77 \%$. The prevalence of mild (Grade I), moderate (Grade II), and severe (Grade III) thinness were $17.31 \%, 4.39 \%$ and $2.07 \%$ respectively. The age specific prevalence of overall thinness was observed to be higher in 10 years $(27.42 \%)$ and lower in 14 years (20.75\%). However, there was no any age-specific trend observed in prevalence of thinness grades among girls. The prevalence of mild thinness ranged $13.75 \%$ (in 11 years) to $21.79 \%$ (in 12 years) (Table 1 ).

Binary logistic regression (BLR) analysis and associations of socio-economic and demographic variables with thinness.

The distribution of prevalence of thinness and results of the binary logistic regression analysis fitted to estimate the crude odds of being affected by overall thinness with the socio-economic and demographic variables are shown in Table 2. Using Chi-square analysis, the prevalence of thinness among was observed to be statistically significant in different categories of birth order (chi-value=7.97; $p<0.01$ ), father's occupation (chivalue $=3.94 ; p<0.05$ ) and family size (chi-value=7.44; $p<0.01$ ). The differences were found to be statistically not significant in age, mother's education, father's education, mother's occupation, house type and income $(p>0.05)$. The result showed that adolescents belonging to the $\geq 3$ birth order and $\geq 5$ member family size exhibited 2.13 times and 1.76 times significantly higher odds for overall thinness, respectively $(p<0.05)$. Similarly, the odds was observed to be significantly 1.71 times higher among those belonging to 'service and others' father's occupational group $(p<0.05)$. However, girls belonging to higher age groups (e.g., 11-12 years and 13-14 years), 'up to $5^{\text {th }}$ standard' father's education, $\geq 6^{\text {th }}$ standard mother's education 'manual worker and others' mother's occupation, non-bricked house types and $\geq$ Rs. 7000 family income exhibited insignificantly higher odds for being thin $(p>0.05)$ (Table 2$)$. 
Table 1: Age-specific subject distribution, descriptive statistics (mean \pm standard deviation) and prevalence of different grades of thinness among the Bengalee girls

\begin{tabular}{|c|c|c|c|c|c|c|c|c|}
\hline \multirow[b]{2}{*}{ Age } & \multirow{2}{*}{$\begin{array}{c}\text { Subjects } \\
\text { (N) }\end{array}$} & \multirow{2}{*}{$\begin{array}{c}\text { Height } \\
\text { (cm) }\end{array}$} & \multirow{2}{*}{$\begin{array}{c}\text { Weight } \\
\text { (kg) }\end{array}$} & \multirow{2}{*}{$\begin{array}{c}\text { BMI } \\
\left(\mathrm{kg} / \mathrm{m}^{2}\right)\end{array}$} & \multicolumn{4}{|c|}{ Prevalence of different grades of thinness } \\
\hline & & & & & $\begin{array}{c}\text { Mild } \\
\text { (Grade-I) }\end{array}$ & $\begin{array}{l}\text { Moderate } \\
\text { (Grade-II) }\end{array}$ & $\begin{array}{c}\text { Severe } \\
\text { (Grade-III) }\end{array}$ & Total \\
\hline \multirow{2}{*}{9 years } & \multirow{2}{*}{55} & 128.97 & 26.49 & 15.85 & 9 & 2 & 2 & 13 \\
\hline & & \pm 6.21 & \pm 4.94 & \pm 2.12 & $(16.36)$ & $(3.64)$ & $(3.64)$ & $(23.64)$ \\
\hline \multirow{2}{*}{10 years } & \multirow{2}{*}{62} & 133.86 & 29.69 & 16.44 & 13 & 3 & 1 & 17 \\
\hline & & \pm 6.83 & \pm 7.09 & \pm 2.99 & $(20.97)$ & $(4.84)$ & $(1.61)$ & $(27.42)$ \\
\hline \multirow{2}{*}{11 years } & \multirow{2}{*}{80} & 139.21 & 33.67 & 17.31 & 11 & 1 & 3 & 15 \\
\hline & & \pm 8.04 & \pm 6.89 & \pm 3.00 & (13.75) & (1.25) & (3.75) & $(18.75)$ \\
\hline \multirow{2}{*}{12 years } & \multirow{2}{*}{78} & 143.65 & 37.27 & 17.92 & 17 & 3 & 1 & 21 \\
\hline & & \pm 7.28 & \pm 8.48 & \pm 3.10 & (21.79) & (3.85) & $(1.28)$ & (26.92) \\
\hline \multirow{2}{*}{13 years } & \multirow{2}{*}{59} & 147.48 & 41.32 & 18.86 & 9 & 5 & 1 & 15 \\
\hline & & \pm 7.01 & \pm 8.39 & \pm 2.95 & (15.25) & $(8.47)$ & (1.69) & $(25.42)$ \\
\hline \multirow{2}{*}{14 years } & \multirow{2}{*}{53} & 151.08 & 46.43 & 20.29 & 8 & 3 & 0 & 11 \\
\hline & & \pm 5.81 & \pm 10.38 & \pm 3.89 & (15.09) & (5.66) & $(0.00)$ & (20.75) \\
\hline \multirow{2}{*}{ Total } & \multirow{2}{*}{387} & 140.68 & 35.65 & 17.72 & 67 & 17 & 8 & \multirow{2}{*}{$92(23.77)$} \\
\hline & & \pm 9.98 & \pm 10.01 & \pm 3.31 & (17.31) & (4.39) & (2.07) & \\
\hline
\end{tabular}

Values are in parenthesis indicates percentages

Table 2: Results of the binary logistic regression (BLR) showing associations of socio-economic and demographic variables with thinness

\begin{tabular}{|c|c|c|c|c|c|c|c|}
\hline \multirow[t]{2}{*}{ Variables } & & \multirow{2}{*}{$\begin{array}{l}\text { Frequency } \\
\text { distribution } \\
(\mathrm{N}=387)\end{array}$} & \multicolumn{2}{|c|}{$\begin{array}{l}\text { Prevalence of Thinness } \\
\qquad(\mathrm{N}=92)\end{array}$} & \multicolumn{3}{|c|}{$\begin{array}{c}\text { Binary logistic regression } \\
\text { Analysis }\end{array}$} \\
\hline & & & Prevalence & Chi-value & Wald & ODDS & $95 \% \mathrm{Cl}$ \\
\hline \multirow{3}{*}{ Age } & $9-10$ years $®$ & $117(30.2)$ & $30(32.6)$ & \multirow{3}{*}{0.33} & & - & - \\
\hline & $11-12$ years & $158(40.8)$ & $36(39.1)$ & & 1.04 & 1.39 & $0.77-2.50$ \\
\hline & $13-14$ years & $112(28.9)$ & $26(28.3)$ & & 1.04 & 1.40 & $0.73-2.68$ \\
\hline \multirow{2}{*}{ Birth Order } & $1-2$ & $323(83.5)$ & $68(73.9)$ & \multirow{2}{*}{$7.97^{* *}$} & & - & - \\
\hline & $\geq 3 \circledast$ & $64(16.5)$ & $24(26.1)$ & & 5.58 & $2.13^{* *}$ & $1.13-4.00$ \\
\hline \multirow{2}{*}{$\begin{array}{l}\text { Mother's } \\
\text { Education }\end{array}$} & Up to $5^{\text {th }}$ standard $®$ & $223(57.6)$ & $60(65.2)$ & \multirow{2}{*}{0.11} & & - & - \\
\hline & $\geq 6^{\text {th }}$ standard & $164(42.4)$ & $32(34.8)$ & & 0.11 & 1.10 & $0.64-1.90$ \\
\hline \multirow{2}{*}{$\begin{array}{l}\text { Father's } \\
\text { Education }\end{array}$} & Up to $5^{\text {th }}$ standard & $229(59.2)$ & $53(57.6)$ & \multirow{2}{*}{0.12} & 0.37 & 1.18 & $0.68-2.05$ \\
\hline & $\geq 6^{\text {th }}$ standard $\AA$ & $158(40.8)$ & $39(42.4)$ & & - & - & - \\
\hline \multirow{2}{*}{$\begin{array}{l}\text { Mother's } \\
\text { Occupation }\end{array}$} & Housewife $®$ & $230(59.4)$ & $54(58.7)$ & \multirow[b]{2}{*}{0.03} & & - & - \\
\hline & $\begin{array}{l}\text { Manual worker and } \\
\text { Others }\end{array}$ & $157(40.6)$ & $38(41.3)$ & & 0.25 & 1.15 & $0.66-1.99$ \\
\hline \multirow{2}{*}{$\begin{array}{l}\text { Father's } \\
\text { Occupation }\end{array}$} & Manual works $®$ & $199(51.4)$ & $53(57.6)$ & \multirow{2}{*}{$3.94^{*}$} & & - & - \\
\hline & Service and others & $188(48.6)$ & $39(42.4)$ & & 4.55 & $1.71^{*}$ & $1.04-2.82$ \\
\hline \multirow{2}{*}{ House Type } & Non-bricked & $333(86.0)$ & 77 (83.7) & \multirow{2}{*}{0.57} & 0.95 & 1.43 & $0.69-2.95$ \\
\hline & Bricked $®$ & $54(14.0)$ & 15 (16.3) & & & - & - \\
\hline \multirow{2}{*}{$\begin{array}{l}\text { Income } \\
\text { (Rupees) }\end{array}$} & $<7,000$ & $163(42.1)$ & 38 (41.3) & \multirow{2}{*}{0.03} & & - & - \\
\hline & $\geq 7,000 @$ & $224(57.9)$ & $54(58.7)$ & & 0.33 & 1.16 & $1.05-2.97$ \\
\hline \multirow{2}{*}{ Family Size } & $1-4$ & $174(45.0)$ & $30(32.6)$ & \multirow{2}{*}{$7.44^{*}$} & & - & - \\
\hline & $\geq 5 @$ & $213(55.0)$ & $62(67.4)$ & & 4.58 & $1.76^{*}$ & $1.05-2.97$ \\
\hline
\end{tabular}

${ }^{*} p<0.05,{ }^{* *} p<0.01$; Values are in parenthesis indicates percentages, $\circledast$ Reference category 


\section{Discussion}

The prevalence of undernutrition is considered to be a major continuing problem throughout India, particularly in the rural areas, where increase rates of poverty, socio-economic disparities and less availability of basic health care facilities are considered to be the main factors. The gradual increase of thinness among adolescents is now a common event in the developing countries like India. Data from many studies suggested that the problem of thinness is persistent transversely among Indian children and adolescents $6,7,8,9,10,11,16,17$. In case of adolescent girls, prevalence of thinness is also associated with the nutritional deficit, menstrual irregularity and various eating disorders. It also affects the reproductive capacity of adolescent girls and young married women, especially among adolescents married at an early age 1 . The overall prevalence of thinness $(23.77 \%)$ in the present study was observed to be higher than the reported studies among rural adolescents of Assam $(19.14 \%)^{24}$, tribal adolescents $(14.90 \%)^{10}$, but lower those Santal girls $(44.60 \%)^{25}$, rural adolescents of North-east, India $(46.89 \%)^{6}$ and Bengalee adolescent girls of North Tripura $(52.98 \%)^{11}$.

Despite of significant economic development in the developing countries, prevalence of undernutrition still remains a major public health issue that contributes to pre-mature mortality and morbidity and several illhealth conditions. The major underlying are poor socioeconomic conditions and environmental, ethnic and demographic disparities ${ }^{13,14,15,16,17,25,26,27}$. Results of the

\section{References}

1. World Health Organization (WHO). Physical status: the use and interpretation of anthropometry. Technical Report Series No. 854. Geneva: World Health Organization, 1995.

2. Sivagurunathan C, Umadevi R, Rama R, Gopalakrishnan S. Adolescent health: present status and its related programmes in India. Are we in the right direction? J Clin Diagn Res 2015;9:LE01-6.

3. United Nations Children's Fund. Ending Child Marriage: Progress and prospects. New York: UNICEF, 2014.

4. Kapil U, Pradhan R. Integrated Child Development Services scheme (ICDS) and its impact on nutritional status of children in India and recent initiatives. Indian J Public Health 1999;43:21-5.

5. Venkaiah K, Damayanti K, Nayak MU, Vijayaraghavan $\mathrm{K}$. Diet and nutritional status of rural adolescents in India. Eur J Clin Nutr 2002;56:1119-25.
BLR analysis that adolescent girls belonging to $\geq 3$ birth order (2.13 times) and $\geq 5$ family members (1.76 times) exhibited greater risks of being affected by thinness $(p<0.05)$. Several researchers have reported that family size and the 'number of sibs' had strongly explanatory powers of undernutrition among children and adolescents ${ }^{17,26}$. A similar study has reported that the children of higher birth order (e.g., $\geq 3^{\text {rd }}$ ) had significantly 2.50 folds $(p<0.05)$ higher risk of undernutrition than those born with lower birth orders ${ }^{27}$. This could be attributed to the socio-economic burden on poor families with several children leading mothers to give less attention to their younger children, whose nutritional status suffered as a consequence of undernutrition. The adolescents belonging to 'service and other' father's occupation has significantly higher (1.67 times) associated with thinness $(p<0.05)$. The father's occupation is considered to be an important contributing factor is occupation, where studies have shown a negative association between nature of parental occupation and child survival in the developing countries ${ }^{16,17}$

\section{Conclusion}

Several socio-economic and demographic variables significantly influenced the overall prevalence of thinness and birth order, father's occupation and family size were identified to be the most important determinant variables. The proper dissemination of awareness related to nutritional requirement, food habit, and appropriate dietary habit would be helpful to reduce the prevalence of thinness.

6. Mondal N. Thinness as major underlying problem among Adolescents of Northeast India. J Nepal Paediatr Soc 2014;34:39-47.

7. Medhi GK, Hazarica NC, Mahanta J. Nutritional status of adolescents among tea garden workers. Indian J Pediatr 2007;74:343-7.

8. Mondal N, Sen J. Prevalence of stunting and thinness among rural adolescents of Darjeeling district, West Bengal, India. Italian J Public Health 2010;7:54-61.

9. Maiti S, Ali, KM, De, D, Bera TK, Ghosh D, Paul S. A comparative study on nutritional status of urban and rural early adolescent school girls of West Bengal, India. J Nepal Paediatr Soc 2011;31:169-74.

10. Mondal N, Terangpi M. Prevalence of undernutrition among tribal adolescents of Karbi Anglong district of Assam, Northeast India. Sri Lanka J Child Health 2014;43:154-7.

11. Saha, S, Sil K. Prevalence of thinness among rural adolescent Bengali school girls of North Tripura. Inter J Sci Applied Res 2015;2:56-8. 
12. Cole TJ, Hegal, KM, Nicholls D,. Jackson AA. Body mass index cut-offs to define thinness in children and adolescents: International survey. BMJ 2007;355:194-198.

13. Gomes Fda S, Anjos LA, Vasconcellos MT. Association between anthropometric nutritional status and socioeconomic conditions among adolescents in Niterói, Rio de Janeiro State, Brazil. Cadernos de Saúde Pública2009;25:2446-54.

14. Melaku YA, Zello GA, Gill TK, Adams RJ, Shi Z. Prevalence and factors associated with stunting and thinness among adolescent students in Northern Ethiopia: a comparison to World Health Organization standards. Arch Public Health 2015;73:44.

15. Mushtaq MU, Gull S, Khurshid U, Shahid U, Shad MA, Siddiqui AM. Prevalence and socio-demographic correlates of stunting and thinness among Pakistani primary school children. BMC Public Health 2011;11:790.

16. Tigga PL, Mondal N, Sen J. Effects of certain socioeconomic, sociodemographic and lifestyle factors on the prevalence of thinness among pre-school children of North Bengal, India. Epidemiol Biostatistics Public Health 2015;12: e10282(1-11).

17. Mondal N, Basumatary B, Kropi J, Bose K. Prevalence of double burden of malnutrition among urban school going Bodo children aged 5-11 years of Assam, Northeast India. Epidemiol Biostatistics Public Health 2015;12:e11497(1-10).

18. Das Chaudhuri, AB, Basu S, Chakraborty S. Twinning rate in the Muslim population of West Bengal. Acta Genet Med Gemellol (Roma) 1993;42:35-9.
19. Lwanga, SK, Lemeshow S. Sample size determination in health studies: A Practical Manual. Geneva: World Health Organization, 1991.

20. Touitou Y, Portaluppi F, Smolensky MH, Rensing L. Ethical principles and standards for the conduct of human and animal biological rhythm research. Chronobiol Int2004;21:161-70.

21. Hall JG, Allanson JE, Gripp KW, Slavotinek AM. Handbook of Physical Measurements. New York: Oxford University Press, 2007.

22. Ulijaszek SJ, Kerr DA. Anthropometric measurement error and the assessment of nutritional status. $\mathrm{Br} \mathrm{J}$ Nutr1999;82:165-77.

23. Sharma J, Mondal N. Prevalence of Double Nutrition Burden among Adolescent Girls of Assam, Northeast India. J Nepal Paediatr Soc 2014;34:132-137.

24. Das S, Bose K. Prevalence of thinness using new international cut-off points among Santal tribal children and adolescents of Purulia district, West Bengal, India. Sri Lanka J Child Health 2011;40:10510.

25. Choudhury KK, Hanifi MA, Rasheed S, Bhuiya A. Gender inequality and severe malnutrition among children in a remote rural area of Bangladesh. $J$ Health Popul Nutr 2000;18:123-30.

26. Mondal N, Sen J. Prevalence of undernutrition among children (5-12 years) belonging to three communities residing in a similar habitat in North Bengal, India. Ann Hum Biol 2010;37:198-216.

27. Biswas S, Bose K. Sex differences in the effect of birth order and parents' educational status on stunting: a study on Bengalee preschool children from eastern India. Homo 2010; 61:271-6. 